\title{
Lo bucólico y lo épico en el poema de Fernando de Valverde: una Virgen pastora y guerrera en tierras peruanas
}

\author{
Bucolic and Epical Mater in Fernando de \\ Valverde's Poem: The Virgin as a Shepherdess \\ and a Warrior in Peruvian Lands
}

Tatiana Alvarado TeOdorika

Academia Boliviana de la Lengua Universidad de Aquino Bolivia, Piso 2

Pje. Issac Eduardo, La Paz. Bolivia

t.alvaradoth@gmail.com

Orcid ID 0000-0002-8452-3276

Resumen: El poema sacro del fraile agustino Fernando de Valverde, Santuario de Nuestra Señora de Copacabana del Perú, es una producción poética dedicada a la virgen de Copacabana sobre la cual se ha trabajado muy poco y que se conoce menos que otras composiciones contemporáneas, como la de Alonso Ramos Gavilán o la de Antonio de la Calancha. Se trata de una obra particular no solo porque cuenta, en sus primeras páginas, con el primer grabado firmado del Perú virreinal, sino por el carácter híbrido de su composición. Si bien se trata de un poema sacro, está "compuesto de épico y bucólico" como reza el prólogo. En el presente trabajo se distinguen algunas características que permitirían discernir los elementos bucólicos y los épicos presentes en este poema sacro.

Palabras clave: Virgen de Copacabana. Fernando de Valverde. Santuario de Nuestra Señora de Copacabana del Perú. Poema épico.
RECIBIDO: 11 DE ENERO DE 2018 ACEPTADO: 26 DE SEPTIEMBRE DE 2018
Abstract: The Augustinian friar Fernando de Valverde's sacred poem, Santuario de Nuestra Señora de Copacabana del Perú, is a composition dedicated to the Virgin of Copacabana that has received little critical attention and is thus less well known than other contemporary poetic works, such as those written by Alonso Ramos Gavilán or Antonio de la Calancha. It is a rather special poem not only because it includes, in its early pages, the first signed engraving from vice-royal Peru, but also because of the hybrid nature of its composition. The present work seeks to set out some characteristics that allow us to identify bucolic and epic elements that can be found in this religious poem.

Keywords: Virgen de Copacabana. Fernando de Valverde. Santuario de Nuestra Señora de Copacabana del Perú. Epic Poem. 
"Ya no hay géneros" Cortázar, 1971. Prólogo a sus poemas ¿Los hubo alguna vez o los inventamos con un fin taxativo o una necesidad de categorías estilísticas?

E n un pequeño pueblo andino colindante con el lago Titicaca en el que se había establecido brevemente la Orden de Santo Domingo de Chucuito en 1565 (hasta que se la expulsó en 1569), se construyó la iglesia de Copacabana. La imagen de una virgen que tallara Francisco Tito Yupanqui ocuparía el Altar Mayor de la Iglesia, en el día de la festividad de Nuestra Señora de la Candelaria, el 2 de febrero de 1583, después de una serie de milagrosas peripecias. ${ }^{1}$ Posteriormente, la orden de los agustinos habría de establecer un programa para legitimar su presencia y dominio en estos territorios, y en 1637 el fraile agustino Fernando de Valverde hallaría, en la comunidad, la iglesia que se había comenzado a levantar en 1631, y contribuiría, según se cree, al diseño del atrio. ${ }^{2}$

Como ha señalado ya Salles-Reese, el simbolismo del lugar que se elige para entronizar la figura que esculpe Yupanqui es triple, pues acoge al ídolo lacustre Copacabana del ciclo colla, al dios Sol incaico y a la virgen María. Por su parte, Mesa y Gisbert $(2011,23)$ evocan las alusiones que hacen Ramos Gavilán y el padre De la Calancha al ídolo de vistosa piedra azul, con cuerpo de pez y cara humana, que daba nombre al lugar (Copacabana), y se refieren a la entronización de la virgen de la Candelaria con el nombre de Virgen de Copacabana, llevada a cabo una vez que la Virgen había vencido al demonio representado en forma de sirena. En este contexto, la etimología que propone Ramos Gavilán para Copacabana en una obra que dedica a la Virgen (anterior a la de Fernando de Valverde) cobra mayor sentido:

1. Fernando de Valverde se refiere a este episodio al final del poema: “¿Mas cómo a tal primor llegar podría, / quien tallas toscas aprendiz hacía? / Pero de tal rudeza en la ignorancia / quiso mostrar la Gracia su elegancia / y que a Tito la torpe inculta mano / impulso le regía soberano / con que a su industria y afición debía / su belleza el trasunto de María. / Esta Venus celeste, virgen pura, / así se hermoseó que ¿quién pudiera / (aunque Timantes animoso fuera) / sino la Virgen misma a su figura / dar alma de hermosura?" (269D). Según Hans van den Berg, los intentos de esculpir una imagen de la Virgen María deben datarse aproximadamente en 1579. Van den Berg (34-46) recopila los datos presentes en las obras de Ramos Gavilán, De la Calancha, De Valverde e incluso Calderón de la Barca para dar un amplio espectro de relaciones y sus convergencias sobre la obra de Yupanqui, quien iniciaría su labor en Potosí con licencia expedida desde Chuquisaca.

2. Ver Sebastián/Mesa/Gisbert 1985; Querejazu. 
copa suena tanto como piedra preciosa, y cabana se deduce desta dición kaguana, que significa lo mismo que "lugar donde se podrá ver". Juntas pues agora las dos diciones y acomodándolas a este dichosísimo lugar, a boca llena y con verdad lo podemos llamar Copacabana, pueblo donde se puede ver la piedra, pues en él ven todos los fieles aquella piedra preciosa [...] Piedra preciosa es María, pues es diamante terso y bruñido en las minas, no de la tierra, sino de los altos cielos. (256)

Como se puede constatar, la relación entre la piedra y el lago desaparecen por completo, y de esta manera Ramos Gavilán aleja el nombre de lo acuático para acercarlo a lo celestial. Sin embargo, mi objetivo no es hacer un estudio histórico-antropológico de la virgen de Copacabana, sino concentrarme en el poema sacro del agustino Fernando de Valverde y destacar los elementos propios de la tradición occidental y los ingredientes épicos y bucólicos que componen su obra. Para ello, es obligado dejar sentado el contexto en el que se escribe y publica el Santuario de Nuestra Señora de Copacabana del Perú. Poema sacro.

El proceso de mestizaje religioso y cultural en América tras el de evangelización es un "viaje de ida y vuelta”, como dice Luján López (194). Esta afirmación se entiende en su integridad en la devoción mariana que, llegada al Nuevo Mundo en las carabelas, dará lugar a la devoción de la Virgen de Copacabana, que se difundirá desde el lugar que le dio el nombre hasta Tucumán, Lima, Potosí, Jujuy, Tumbaya, Río de Janeiro, Panamá, Valdivia; y luego hasta España e Italia. El culto de la Virgen de Copacabana llegará a España de la mano de otro agustino, Miguel de Aguirre, que nace en una familia noble y acaudalada en la Ciudad de La Plata o Chuquisaca (actual Sucre, Bolivia) en 1598, y será discípulo de Fernando de Valverde. Aguirre estudia Gramática y Filosofía en el Colegio San Martín de Lima y no solo ocupa la cátedra de Teología en la Universidad de Lima, es además calificador y consultor de las juntas secretas del Santo Tribunal. Por otro lado, recibe la cátedra supernumeraria de Prima de Teología Escolástica o cátedra del Maestro de las Sentencias y es prior de los conventos de Lima, La Plata, Copacabana y Collegio. ${ }^{3}$ En abril de 1650, Aguirre deja tierras americanas, para unirse, según parece, a los Descalzos, y el 8 de abril de 1652 instala la primera imagen de la virgen de Copa-

3. Ver Gutiérrez Meza (2017). Se trata de un reciente e imprescindible trabajo que recopila los datos conocidos sobre el agustino y esclarece otros tantos de su biografía. En la cátedra de Prima supra numeraria sería reemplazado al cabo de seis años, en 1648, por otro de los discípulos de Fernando de Valverde: Bernardo de Torres. 
cabana en suelo español en el colegio de doña María de Aragón, en Madrid. Esta sería la primera de muchas otras que instalaría Aguirre en el Viejo Mundo en un impulso de difusión del culto. ${ }^{4}$

En este proceso de difusión, las estampas y los grabados también desempeñan un papel capital. Uno de ellos, el primer grabado firmado del Perú, es obra de otro agustino, fray Francisco Bejarano. Se puede ver en él a María sobre toda Sudamérica inserta en el globo terráqueo; a ambos lados hay dos doncellas representando la Fe y la Gracia, y al pie podemos ver un indígena adorando un ídolo (Estabridis Cárdenas 102-09). Este grabado antecede al poema sacro de fray Fernando de Valverde, Santuario de Nuestra Señora, obra posterior a otras dos más conocidas, de dos agustinos, dedicadas a la virgen: la de Alonso Ramos Gavilán, Historia del célebre santuario de nuestra señora de Copacabana y sus milagros e invención de la cruz de Carabuco (Lima 1621); y la de Antonio de la Calancha, Corónica moralizada del Orden de San Agustín en el Perú (Barcelona 1638).

Fray Fernando de Valverde, hijo de don Rodrigo de Saavedra y de doña María de Valverde, nace en Lima, según afirma Martínez (235). Después de haber estudiado en el colegio de San Martín, dirigido por la Compañía, pasa al convento de San Agustín y luego al Colegio-Universidad de San Ildefonso (bajo la dirección de los agustinos). En 1615 recibe una medalla de oro por su poesía latina en el certamen mariano organizado por la Universidad de San Marcos, y, además de estos versos, compone: la Panegirica Actio gratiarum en honor del Ilmo. Dr. Don Feliciano de la Vega (Lima 1633), el tratado De Trinitate (que se creía perdido en su camino a Europa para su impresión, pero que se conserva en la Biblioteca Real de Bruselas), la descripción de Las Honras Fúnebres hechas en Lima a Su Majestad Felipe III (1621), la Relación de las fiestas de Lima al levantar estandarte por Felipe IV (1622), el Santuario de Nuestra Señora de Copacabana del Perú (Lima 1641), el Sermón sobre la Esclavitud de los devotos del Santo Cristo de Burgos, en el convento de San Agustín de Lima (1649), y la Vida de Nuestro Señor Fesucristo, Dios y Hombre, Maestro y Redentor del mundo (Lima 1657).

Valverde es más bien conocido por su Vida de fesucristo, nuestro Señor, DiosHombre, Maestro y Redentor del Mundo, que tuvo al menos ocho ediciones y fue incluso traducida al francés. Martínez (235) afirma que debido a la resonancia que tuvo la obra en Europa se hizo una impresión en Madrid en 1669, que a

4. Al respecto, Gutiérrez Meza (2014) compendia la propagación del culto a la Virgen de Copacabana y se refiere, además a la composición de La aurora en Copacabana, de Calderón de la Barca, como resultado del auge del culto de la Virgen en la Península. 
causa de los errores que contenía fue denunciada y dio lugar a un proceso inquisitorial del que no se la pudo rescatar sino hasta 1687. En cuanto al Santuario de Nuestra Señora de Copacabana en el Perú, si bien la obra despierta un inicial interés debido al grabado de fray Francisco Bejarano, Sabena $(2014,115)$ considera esta obra una "pieza fundamental del ciclo del gongorismo peruano". ${ }^{5} \mathrm{En}$ este sentido, el presente trabajo quiere ser un aporte en el estudio de esta obra, al concentrarse en el aspecto genérico que le atribuye su propio autor: el épicobucólico, sin dejar de prescindir de su carácter místico inherente.

El poema, compuesto de 18 silvas, ${ }^{6}$ viene precedido de la aprobación del fraile agustino Juan de Ribera (catedrático de Vísperas de Teología en la Universidad de Lima y Calificador del Santo Oficio), de don Andrés de Vilela (oidor del Concejo de su Majestad en la Real Cancillería de la Ciudad de los Reyes) y de don Pedro de Ortega Sotomayor (catedrático de Prima de Teología en la Real Universidad y Calificador del Santo Oficio) y se imprime con la licencia de otro agustino: fray Pedro Altamirano.

\section{UN POEMA MÍSTICO QUE SE REIVINDICA ÉPICO Y BUCÓLICO}

Valverde encuentra la inspiración para su poema en un viaje que hace de Cuzco a Copacabana, al santuario que se había fundado en honor de la Virgen. Se trata de un poema que, si bien se califica de "sacro" a partir del título, en el prólogo se recalca que es "heroico"; es un poema "compuesto de épico y bucólico", como afirma Valverde, pues la materia que trata es propia de la épica, aunque el espacio es una estancia pastoril y los personajes principales, pastores y ganaderos. Para dar fundamento a su composición, Valverde se refiere a lo elevado de las églogas de Virgilio, y a la Poética de Aristóteles para recordar que, como el poema no celebra a persona sino a acción, ${ }^{7}$ introduce a la Reina de los Ángeles como pastora, sin faltar al decoro.

5. Sabena presenta una primera aproximación, más bien descriptiva, al poema sacro de Valverde, concentrándose, sobre todo, en el prólogo. Más recientemente Sabena (2016) ha dado los primeros pasos hacia un análisis comparativo, desde el punto de vista del gongorismo, del poema sacro de Fernando de Valverde y El apologético en favor de don Luis de Góngora de Juan de Espinosa Medrano, que se publicó 22 años más tarde.

6. Un análisis secuencial de poema se encuentra en Gisbert.

7. Aristóteles, en su Poética, afirma que en la epopeya "los pensamientos y la elocución han de estar bien elaborados" (1459b), que en ella "tiene más cabida lo irracional, por lo cual se produce en ella con mucha frecuencia lo maravilloso [...] y lo maravilloso es agradable" (1460a) y que "se dirige a un público distinguido" (1461b). Lo dice comparándola a la tragedia. 
Sabena sostiene que el autor "ofrece un mosaico de autoridades como sostén de un poema que no sigue con rigurosidad las reglas aristotélicas para su conformación sino que practica una apropiación variada y desigual de las tradiciones que lo anteceden" (Sabena 2014, 116). ${ }^{8}$ Esto no debería sorprender, porque, por un lado, en el siglo XVI ya se había desarrollado en Europa la épica culta renacentista que había nacido en Ferrara, con Boiardo y con Ariosto, cuyo Orlando Furioso traduciría Jerónimo de Urrea en 1549 (aunque 30 años más tarde formaría parte del índice de libros prohibidos del inquisidor Quiroga).9 Tasso "cristianizaría” la épica, y su Gerusalemme liberata sería, desde su primera edición, en 1581, fuente de referencia e inspiración, y su primera traducción al castellano vería la luz muy rápidamente, en 1587 . Por otro lado, a esta breve lista de obras de cuya lectura disfrutó, sin duda, Valverde, podría añadirse La Araucana de Alonso de Ercilla (1569), Os Lusiadas de Luis de Camoens (1572), que traduciría Enrique Garcés en el Perú a finales del XVI (traducción que se publica en Madrid en 1591), o el Arauco domado de Pedro de Oña (1596). ${ }^{10}$ Ante una tradición tan larga, tan variada y de tantos continuada, Valverde tiene la posibilidad de apropiarse de los elementos de su predilección en la composición de su poema, sin adscribirse únicamente y de forma rigurosa a las reglas aristotélicas.

La ficción que teje Valverde atiende a la filosofía moral y natural, y a la teología escolástica y mística, como explica el propio autor en su prólogo. ${ }^{11}$ Con estas pocas palabras, el agustino se inscribe en una tradición que alinea poesía, teología y filosofía moral y natural, siguiendo el ejemplo de Dante, Petrarca o Boccaccio (Tubau 324); y en lo que se refiere a la teología escolástica

8. Remito a este artículo para lo que se refiere a la clasificación genérica del poema como la explica y argumenta Fernando de Valverde en su prólogo.

9. Firbas (71) recuerda, además, que el libro circularía rápidamente entre España y América.

10. A decir de Firbas (77), "la imitación de poemas épicos más prestigiosos podía también operar de forma indirecta, a través de los abundantes romances que estos habían inspirado, como los que procedían del Furioso o La Araucana".

11. Además de su adscripción a distintos géneros literarios, Valverde hace referencias explícitas que aparecen en el prólogo del poema, señaladas al margen. Se puede mencionar (en orden de aparición) a Justo Lipsio, Diva Virgo Hallensis; Platón, Convivio [o El discurso de Alcibiades]; Platón, Timeo; Solórzano Pereira, De indiarum iure; Lucrecio, De rerum natura [De natura rerum. Libro 4]; Antonio Possevino, Bibliotheca selecta; Virgilio, Égloga 4; Constantino, Oratio ad sanctorum coetum; Aristóteles, Poética; Clemente Alejandro, Orat ad gentes; Fray Luis de León, Cántico espiritual; Adrianus Turnebus; Angelo Poliziano; Jacobo Pontano; Teócrito, Idilios; Paulo Serlogo, Anteloquio; Tranquilo citando a San Isidoro; Platón, Ion; Lactancio Firmiano, De divinis institutionibus adversus gentes; Pinciano, Filosofía antigua; Platón, Fedón; Horacio, Carmina; y poemas de San Gregorio Nacianceno. 
y mística, parece seguir a San Juan de la Cruz, que congrega ambas, como lo explica él mismo en un pasaje del prólogo al Cántico espiritual donde se dirige a la madre Ana de Jesús: "aunque a Vuestra Reverencia le falte el ejercicio de Teología escolástica con que se entienden las verdades divinas, no le falta el de la mística, que se sabe por amor, en que no solamente se saben mas juntamente se gustan" (53).

Contrariamente a lo que afirmara Sabena $(2014,121)$, Valverde sigue, en la estructura inicial del poema, los puntos y el orden que rige la preceptiva clásica desde Homero (invocatio, propositio, narratio). Se invoca en los primeros versos a la "Reyna de ambos mundos":

con voz heroica y épicos alientos

(si en lira de bucólicos acentos), nuevo cisne te cante, ¡oh, Virgen pura!, en gratos ojos lágrimas vocales entre murmurio blando nazcan en tus amores espirando y logre de tu culto en los elogios ya por cisne, que muere, ser oído, ya por hombre, que espira, ser creído. $(1 \mathrm{G})^{12}$

\section{DE LOS NOMBRES DE LOS PERSONAJES QUE SE INSCRIBEN}

\section{EN LA TRADICIÓN OCCIDENTAL}

Se ha hecho alusión al mosaico de autoridades que Valverde despliega en su prólogo; de la misma manera, los seres mitológicos que pueblan los versos y los nombres de los personajes son también un mosaico que atestigua la tradición humanística en la que se inscribe el poema. Podría empezar refiriéndome a Amarili o Marfisa, por ejemplo.

El nombre de Amarili es el que recibe la divina pastora. La elección del nombre, además de corresponder al espacio bucólico, ya desde Virgilio, sitúa la obra en un espacio de diálogo entre el Nuevo y el Viejo Mundo pues nos

12. Cito a partir de Fernando de Valverde, Santuario de Nuestra Señora de Copacabana en el Perú. Poema Sacro, Lima, con licencia, aprobación y privilegio de diciembre de 1640. Empecé citando por folio y con la letra correspondiente que aparece en margen pues encontré fallos en la signatura, sin embargo, más adelante caí en la cuenta de que también había fallos en la numeración de folios. Los señalaré con sic entre corchetes. Puntúo, acentúo y modernizo el texto, excepción hecha de los vocablos con valor fonético. 
remite, inevitablemente, a la carta que Lope de Vega recibiera y publicara en 1621, en su Filomena, bajo el título de "Amarilis a Belardo", seguida de su propia respuesta: "Belardo a Amarilis"; una breve correspondencia que, desde los fundamentos de la epístola horaciana, surge en el Virreinato del Perú y busca su respuesta en la Metrópoli, donde llega y la encuentra. ${ }^{13}$

En torno a nuestra Amarili se mueven unos personajes que son característicos de sus acciones: Graciano, que blasona a la Gracia como madre (35F); Adamio, que se dice hijo de la Naturaleza, y que toma el nombre de Adán (21E); y Megerino, hijo de la Furia. El poema da cuenta del recorrido (accidentado) de ascenso y purificación espiritual de los pastores. Estos no pueden considerarse como indígenas (interpretación que propone José Antonio Mazzotti 441, quizás con un ánimo de lectura criollista), pues no hay referencia explícita que permita designarlos como tales salvo que las escenas se desarrollan entre Chucuito y Copacabana.

La primera historia que se relata en el poema es la que relata Marfisa, un personaje cuyo nombre nos remite a la tradición épica italiana, y, como Ariosto hiciera con la Marfisa de Boiardo, Valverde lo hace con ambas. ${ }^{14}$ Según dice Marfisa, un sátiro es el que hace pública la profecía que en la corteza de un cedro hermoso había hallado inscrita:

\section{Gratas ostentaciones}

de gozos apercibe

América dichosa peruntina, que ya una ninfa, a toda luz divina, de tus regiones en augusto espacio, trata erigir benigna su palacio

con que tendrás al cielo en selva tuya, que sacras glorias en tu clima influya. $(5 \mathrm{~F})$

El relato del sátiro adquiere un tono místico a partir de la amenaza de las flechas ("rayos sabrosos de hechiceras iras", 7C). Cuanto más fuerte es el ataque,

13. La edición crítica más reciente con la que contamos es la de Vinatea Recoba. Ver, además, el más reciente estudio sobre esta obra en el que se recopila toda la bibliografía sobre el tema: Aladro/Ramos-Tremolada.

14. No es necesario volver sobre la presencia y la influencia de la literatura italiana en el Virreinato del Perú: Petrarca, Dante, Ariosto, Tasso y tantos más influirían en Diego Dávalos, Diego Mexía de Fernangil, Alonso de Ercilla o Pedro de Oña, entre otros (ver Bellini). Marfisa, en Boiardo, es una mujer guerrera, insensible al amor, caprichosa, irascible y colérica. En Ariosto, si bien conserva su carácter intolerante, aparece más dócil y humana. 
mayor es su deseo de agonía y de sentir sus entrañas malheridas. A esta narración inicial sigue la de Graciano, un personaje en el que vale la pena detenerse, no necesariamente porque el nombre nos remita a una tradición en particular, sino sobre todo porque se trata de uno de los personajes principales. Abrasa a Graciano, que es "amante divino" (204D), el deseo de ver a su divina zagala (9F); la pastora de los montes de Copacabana es la razón de la adoración del místico pastor que vive en un valle cercano a la ciudad de Chucuito, una adoración que añade al género híbrido épico-bucólico que el poema reivindica un carácter místico incontestable:

Graciano, pastor el más dichoso, tiernos gozaba de su amor favores, dejándole, las glorias que lograba entre ambición de más gozar, quejoso; si bien rendido a esfuerzos dominantes, dulzuras de seráficos amores, no las gozaba ya, las padecía. (2F)

El espacio bucólico por el que caminan los pastores integra el antártico mundo a la tradición:

jardín florido y bosque religioso, de amenidad y amparo sombra hacía al lago más jayán y más hermoso, que desde el rojo Oriente al pardo Ocaso y del Septentrión al Mediodía, la más atenta vio cosmografía pasar pudiera por undoso seno del peruntino sur, si mar profundo coronarse con sus ondas no le impide, que según los geógrafos decretos, no hay dos Mediterráneos en el mundo. (10B)

El mediterráneo de estos versos es Terebino, “el joven más hermoso / que en verdes bosques concibieron Drías" (11F). Terebino representa lo que es hoy el lago Titicaca y que en el poema es una isla ("la gran Titicaca / isla profunda del sublime lago" 182D). Alrededor de Terebino, la hermosa ninfa Pasítea, "viviente espuma / de amor" (12D), funda un imperio en el mundo antártico, a pesar de la envidia de Tetis, en un espacio ameno que los versos sitúan en el 
mapa del mundo alegando su supremacía de Oriente a Occidente y de Norte a Sur. Se podría hablar de una translatio deorum que responde a una tradición que ya se había establecido en el Nuevo Mundo, pues respondía a la formación humanística de los hombres letrados. Circunscribiéndome al espacio peruano podría referirme comparativamente al Discurso en loor de la poesía, donde Clarinda da prueba del traslado del dios Apolo al mundo antártico, en la figura de Delio (sobrenombre de Mexía de Fernangil) $;{ }^{15} \mathrm{o}$ a la Relación de viaje al Nuevo Mundo de fray Diego de Ocaña, donde, a pesar de tratarse de una crónica, se habla del dios Sol de los quechuas bajo el nombre de "Apolo". ${ }^{16}$

En este espacio de armonía "donde todo lo viste refulgente lumbre" (31F), los habitantes del antártico pensil reciben con ojos de espanto la llegada de Adamio, a quien se describe como el más funesto parto de Érebo,

Del que Trinacria lúgubre cabrío

el crudo repastaba Polifemo, impíos renuevos son: color leonado

que llama anima del tartáreo estío, secretas garras, erizado el pelo, en los obscenos ojos torpe celo. (17C)

Adamio es "hijo de la tierra", si nos remitimos a la etimología hebrea, y los versos que lo describen nos remiten al Génesis como hipotexto bíblico. Su aspecto salvaje, como asevera él mismo (23F), es prueba de su desconocimiento de Dios, su padre eterno e incorpóreo, tal como le revela su madre, la Naturaleza. Al saberse hijo de Dios, Adamio pide a su padre que le adjudique el caudal que le corresponde (un tanto a imagen de Faetón ante el Sol) (21 [sic por 22] D-E), pero al darse cuenta de su error, y habiéndose despertado en él el arrepentimiento, Adamio empieza un penoso deambular en el que busca incluso a la Muerte, que rehúsa llevárselo (28C-E). Una voz luciente anuncia a Adamio que solo una hermana suya le restituiría el favor del Padre, y que aquella era María (29G-30B). María resulta ser, siguiendo el relato de Adamio, no solo hermana suya, sino la hija con la que Dios decidiera desposarse $(35 \mathrm{G})$.

La historia de Adamio suscitará un franco diálogo filosófico entre los pastores en torno a la Gracia y si esta eleva o no al hombre a ser divino; es enton-

15. Por lo pronto, solo contamos con la edición facsimilar que Trinidad Barrera hace la Primera parte del Parnaso Antártico de obras amatorias de Diego Mexía de Fernangil, donde se encuentra el Discurso en loor de la poesía.

16. La mejor edición de la Relación de Ocaña es la que Beatriz Carolina Peña publica en 2013. 
ces cuando se gesta, en el poema, la travesía épica del personaje mariano. La heroicidad de María, a quien debemos la Gracia mayor, se vislumbra en la silva IV, ${ }^{17}$ donde se explica, además, la necesidad de Dios de haber creado primero a María, por su condición de mujer, pues necesitaba serlo para ser madre:
Mujer será María verdadera, mas de maternidad la excelsa Gracia
tan íntima en su ser primero impera, que puesta la atención en su eficacia
diré que menos fue mujer que madre,
y que aún el ser que tuvo femenino
ciertas luces gozó de ser divino. (56G-57A)

\section{DESVELANDO LAS CARACTERÍSTICAS ÉPICAS}

Si bien la heroicidad de la Virgen se vislumbra desde su maternidad, los versos que sientan las bases del relato heroico mariano van a reforzarse, en la misma silva, con una aparición:
Pasó veloz la súbita tristeza,
y registrando el bosque de la frente,
vieron que como en la mina viviente
crecía en él, al paso de su vida,
una hermosa mujer del sol vestida,

17. "Teologizaros quiero los instantes / que en la Paterna Mente / formaron este título eminente. / Sabed que al primer hombre / crió el Supremo Artífice en un parque, / donde en lisonjas dulces la[s] delicias / sabias le hacían al vivir caricias. / Determinó cobrar de él, por tributo, / la obediente abstinencia en solo un fruto, / pecó infeliz, el trágico delito / creciendo con infames circunstancias, / pues se rindió cobarde a un apetito, / armas teniendo para dar batalla / a la envidiosa de Plutón canalla. / Pedía la justicia instantemente / que se diese castigo al delincuente, / pero de la clemencia a los halagos / dulcemente rendido, / y ya más blando y tierno / el Padre, que ofendido, / gusta que el Verbo eterno / haciendo de su cruz y muerte paga, / por el traidor Adán le satisfaga. / Fue luego consiguiente y necesario / que se vistiese Dios de Humana carne, / donde Cloto homicida / atreviese tijeras a su vida, / único siendo de encarnar motivo / rescatar del Averno a Adán cautivo [...]. / Habiendo de ser hombre el Verbo eterno, / fue preciso y conexo darle madre / tan soberana y bella / que digna tanto sol pariese estrella. [...] / pues a madre del Verbo, por derecho, / se le debe la Gracia más crecida / que puede dar vivir a humana vida" $(55 \mathrm{~B}-\mathrm{G})$. La idea de Adán traidor parece también circunscribirse en una tradición: ya en el siglo XII, Bernardo de Claraval califica de esta manera a Adán en su sermón tercero del día de la circuncisión del Señor (In circuncisione Domini); también el jesuita Juan Eusebio Nieremberg, en De la perfección religiosa. A una religiosa descalza (en el capítulo I "Del bien de la vocación religiosa, por ser Dios el que llama"); y en el campo artístico, Lope de Vega se sirve del adjetivo en su comedia La primera información. 
que con rostro inclinado, a lo piadoso, en el indiano mundo parecía

que resplandores bellos influía, viviendo con su lumbre

flores el valle y oro la ardua cumbre. (59G-60A)

Desde aquí, el relato heroico avanza con interrupciones narrativas y de diálogo filosófico. Cada uno de estos diálogos merecería ser analizado en detalle desde la filosofía moral y natural, y desde la teología escolástica y mística, como mueve a hacerlo el autor en su prólogo. Pero volviendo a lo heroico, la primera hazaña de María es el combate que libra contra el amor profano (silva VI), atendiendo al llamado de los pastores que clamaban su presencia para frenar las atrocidades de Venus y Cupido. Respondiendo a estos lamentos, se presenta aguerrida:

De su Copacabana a nuestros montes

(que por ser de su feudo, son sagrados)

vino Amarili armada de su celo, alistándose al punto por soldados, en la bandera suya el orbe, y cielo. [...]

Pasósele a veneno vengativo

la que empezó ternura, y a rígida amargura

lo dulce de su afecto compasivo; y solo con mirar los malhechores casi resueltos los dejó en pavores: que ojos en que el materno amor herido de sus hijuelos al amparo asoma, de basilisco son, no de paloma. (77F-G)

Amarili vence a Venus y a Cupido en batalla, pero esta termina descrita en tono místico:

gustas matar de hermosa, mas no para el triunfo en esa muerte sino en que muera y viva el alma en verte, matando con ardides tan galantes que no difinirán los más atentos si aquella es muerte o es vivir de amantes. (87 [sic por 88] в) 
Así, vencido el amor profano, hace su aparición en el relato la representación angélica de Venus. Llama la atención que Valverde haya elegido precisamente al arcángel Haniel (una aparición muy poco usual dada la época), que, en el entramado cabalístico del Renacimiento, corresponde a Venus. Haniel, lloroso, pide piedad a Dios por la sangre que se derrama en campos peruvios, recordándole que Él había puesto en sus manos el cuidado del Perú (96A-F). Dios agradece el empeño del arcángel y le confiesa:

Mirando estaba, cuando aquí llegaste, los campos del Perú en su sangre misma antes que a mi corona conducidos con crueldad teñidos.

$\mathrm{Y}$ si bien que mi fe, con tantas armas, a la peruvia penetrase gente, fue de Mi providencia el expediente que en el valor de altísimas razones empleó desveladas atenciones. Pero ya recoger el duro acero de sangre embriagado peruntina a la cinta en clemente vaina quiero, trocando en medras la fatal ruina, pues ya estrañaba Mi piedad paterna que a quien sangre de Dios buscó vertida le costase el hallar a Dios la vida. $(97 \mathrm{D})^{18}$

En estos versos en los que se reconoce a un Dios más bien veterotestamentario, que castiga y es a la vez clemente, se anuncia que el remedio del Perú sería María, y como prueba de ello, los pastores dan cuenta de sus milagros: el restablecimiento del indio Topa, que vuelve a caminar ya sin muletas (40 [sic por 100] A-C); o el rescate, en Potosí, de la gente que había quedado sepultada bajo todo un monte y que tras ocho días de agonía había logrado salvarse gracias al amparo de la Virgen (40 [sic por 100] G). Los milagros son, como dice la mismísima Virgen en la silva VIII, medios para entablar la fe en los indios. Ante la hegemonía mariana, la idolatría agraviada aparecerá entre gemidos, pero huirá ante la aparición de doce estrellas que bajarán para coronar a

18. Son sugestivas las semejanzas entre estos versos y los versos 6-112 de la "Imitación de Italia mia" de Enrique Garcés. Ver Garribba y Alvarado Teodorika. 
María reina. Los milagros, si bien son elemento constitutivo del relato mariano, también responden a la necesaria presencia de lo maravilloso en la épica, siguiendo los planteamientos aristotélicos: "Es preciso incorporar a las tragedias lo maravilloso; pero lo irracional, que es la causa más importante de lo maravilloso, tiene más cabida en la epopeya, porque no se ve al que actúa" (Poética 1460a10).

En este punto del relato, se determina en tribunal celeste y se envía al presidente de la Audiencia de la Plata (entiéndase Charcas) la noticia de que el santuario en Copacabana habría de encomendarse a la orden de los Agustinos. Tras haber atravesado las aguas del Terebino los pastores se encontrarán con el último personaje clave del poema, Megerino. Si bien Graciano se sabe hijo de la Gracia desde los primeros versos, y si Adamio desvela ser hijo de la Naturaleza pero va en busca de la divina María; Megerino explica haber sido hijo de la Gracia y haber perdido a la madre por soberbia y arrogancia (140E). Se trata de un personaje clave pues, como dictan los versos del poema:

Celebran en Adamio y Megerino

dos grandes glorias del poder divino:

pues si en Adamio vence los despeños

de la Naturaleza mal regida,

triunfa en Megerino altivos sueños

de arrogante insolencia descreída. (159F)

Además de las acciones heroicas de María y de la irrupción de lo maravilloso a través de los milagros, otra de las características del relato heroico, que se reconoce en el poema, es el uso del epíteto épico. Se designa constantemente a María como guerrera: es "la bélica María" (72 [sic por 102] F; 185D), "bélica deidad, mejor Belona" (74 [sic por 104] A), "Belona más galante" (153E), "la Belona bellísima, María" (185в). Se constata su belicosidad, no solo a través de la acción y del epíteto, sino además, a través del traje con el que aparece su "hija", la Gracia, cuando se presenta bajo el nombre de Carinda y habla de su traje:

este, amigo, lo es de cazadoras de ciertas fieras que este bosque cría: feroces y sangrientas son algunas; otras, por halagüeñas, importunas. $Y$ porque me aborrecen, en matarme todas han conspirado, o lastimarme. 
Por aqueste respeto siempre armada

ando de peto fuerte y de celada,

arco traigo y aljaba, con que sigo

sangrienta aún por el aire a mi enemigo. (207D)

A tal punto se apropia la Gracia del traje, que hacia el final del poema le pesará a Graciano no haber reconocido a su propia madre por al atuendo que llevaba.

En la exposición de las características a las que vengo refiriéndome, es también significativa la congregación de marcas épicas que van a darse cita en las últimas silvas del poema: no solo la aparición de la Gracia bajo prendas marciales tiene un viso (pero al revés) de Atenea en traje de anciano o de mendigo; además, las aventuras a las que va a tener que enfrentarse Graciano, guiado de Carinda, son una suerte de amalgama de cantos odiseicos. Carinda conduce a Graciano por los montes en busca de sus amigos pastores, los amigos que había perdido de vista tras una tempestad. Los encuentra (y reconoce a pesar de parecer "cadáveres o máscaras avernas", 215B) en una gruta en la que un gigante, mitad cíclope, mitad paria, los amedrenta y quiere devorarlos. Graciano tranquiliza a su amigo Sereno con el divino "licor almíbar" (218A) que le diera Carinda y sigue su camino en busca de los demás pastores. Los encontrará en un paraje no muy lejano, incapaces de distinguir sollozos y alaridos del júbilo y el regocijo, que es lo único que escuchan. Graciano no puede sacarlos de ese letargo, cuya descripción evoca el episodio de los lotófagos, pero logra su cometido con la ayuda de una pastorcilla que, enternecida, los sacará del encanto con los versos de un salmo (220B). Otros pastores aparecen convertidos en leones, lobos y toros; consecuencia del hechizo de una maga que se sirve de plantas para hacer "lisonjas al olfato" (221C). El hechizo sucumbe ante la fragancia de rosas, jazmines, azucenas y acantos (221D): flores marianas todas ellas. ${ }^{19}$ Si bien los paralelos con la Odisea de Homero son evidentes, Valverde siente la necesidad de desvelar su fuente clásica al lector y declara el nombre de la maga: Circe, y su esclarecimiento confirma la sospecha inicial del advertido lector.

Más adelante, son Adamio y Megerino, atrapados en cuerpos de lobo, los pastores que quedan por redimir. La inconsolable tristeza de Graciano al ver-

19. Las dos primeras flores se han considerado representación simbólica de la virgen María. Entre otros, Sedulio compara a la virgen María con una rosa (II, col. 596) y Dante asocia la rosa con la virgen ("Paraíso", canto XXIII, p. 569). De la azucena decían los antiguos que tenía la virtud de neutralizar los encantos y enojar el peligro, y el acanto alerta del nacimiento de una nueva primavera. 
los es tal que Carinda trata de salvarlos de su propia mano con un nuevo brebaje, pero una nueva maga se lo impedirá. Ante los hechos, Carinda se ve obligada a insistir, dar guerra y desvelar su identidad: como Gracia da inicio a un enfrentamiento retórico para que el "santo pensamiento" venza "al ciego entendimiento" (227E), y la maga la desafía reclamando la presencia de sus hijas, las Delicias, que saldrán al paso de los pastores en emboscada (228F) con el objetivo de ganar la atención de Adamio y Megerino con lisonjas (229A-D). Los pastores triunfarán ante ellas siguiendo el consejo de Carinda: "no escucharlas ni verlas" (229E), como vencieran los compañeros de Ulises la dulzura y la ternura de los cantos de sirenas que los sumían en una especie de letargo.

El poema de Fernando de Valverde se inscribe, sin duda, en una larga tradición, como se ha podido confirmar a través de lo expuesto. Convergen en él personajes de la mitología clásica, elementos de gesta y características tradicionales de la iconografía mariana que se expresan en un versificar gongorino. Valverde hace converger cada una de estas tradiciones y las ancla en un contexto geográfico nuevo a través de elementos que hacen referencia a la realidad local (referencia al indio Topa, a un monstruo lacustre o a anansayas y urinsayas, por ejemplo, con episódicas apariciones). No solo se congregan en torno a María amantes pastores, debates retóricos o milagros peregrinos, sino también monstruos y diosas recelosas que peregrinan por nuevas tierras. "Las palabras se transportan”, como diría Roland Barthes (87), y con ellas todo un nuevo imaginario que va a pasar a enriquecer el imaginario peruano. Valverde logra su cometido y se reconoce, en el poema sacro que compone, la acción épica en un entorno de estética bucólica.

\section{OBRAS CITADAS}

Aladro, Jordi, y Ricardo Ramos-Tremolada. "La Epistola de Amarilis a Belardo, una misiva del Perú mestizo a España”. Hipogrifo 3.1 (2015): 69-87.

Alvarado Teodorika, Tatiana. "Enrique Garcés y la continuidad de la literatura política en los Andes, Iberia e Italia”. Laberinto fournal 9 (2016): 94-127.

Aristóteles. Poética. Trad. Antonio López Eire. Fundamentos 201. Madrid: Istmo, 2002.

Barthes, Roland. Roland Barthes por Roland Barthes. Caracas: Monte Ávila Editores, 1997.

Bellini, Giuseppe. "Presencia de la literatura italiana en la América hispana de los siglos XVI-XVII". España e Italia: un encuentro de culturas en el Nuevo 
Mundo (Atti del Colloquio Italo-Spagnolo, Barcelona 20-22 Aprile 1989). Roma: Bulzoni, 1991. 37-57.

Cruz, Juan de la. Declaración de las canciones que tratan del ejercicio de amor entre el alma y el esposo Cristo [Cántico espiritual]. Ed. Paola Elia. L'Aquila: Textus, 1999.

Dante Alighieri. Divina Comedia. Trad. Ángel Crespo. Barcelona: Planeta, 1983. Estabridis Cárdenas, Ricardo. El grabado en la Lima virreinal: documento bistórico y artístico (siglos XVI-XIX). Lima: Universidad de San Marcos, 2002.

Firbas, Paul, ed. Juan de Miramontes Zuázola. Armas antárticas. Lima: Pontificia Universidad Católica del Perú, 2006.

Garribba, Aviva. "El compromiso civil cruza las fronteras: la imitación de Italia mia de Enrique Garcés, traductor del Canzoniere". Frontiere: sogli e interazioni. I linguaggi ispanici nella tradizione e nella contemporaneità, I: Letteratura. Eds. Alessandro Cassol, Daniele Crivellari, Flavia Gherardi y Pietro Taravacci. Labirinti 152. Trento: Università degli studi di Ttrento, 2013.269-86.

Gisbert, Teresa. "Los ángeles en el lago Titicaca (Análisis secuencial del poema de Valverde)". Saberes y memorias en los Andes. Dir. Thérèse Bouysse Cassagne. Paris: IHEAL, 1997. 213-35.

Gutiérrez Meza, José Elías. "El culto de la Virgen de Copacabana en España y la fecha de composición de La aurora en Copacabana". Anuario calderoniano 7 (2014): 167-78.

Gutiérrez Meza, José Elías. "Fray Miguel de Aguirre, el viajero de Copacabana". Viajeros, crónicas de Indias y épica colonial. Eds. Mariela Insúa y Jesús Menéndez Peláez. New York: IDEA, 2017. 91-105.

Luján López, Francisco. "Nuestra Señora de Copacabana, una devoción andina patrona de Rubielos Altos (Cuenca): su origen y difusión". Revista Murciana de Antropología 8 (2002): 193-246.

Martínez, Gregorio, O.S.A. "Un manuscrito inédito de Fernando de Valverde". Boletín del Instituto Riva-Agüero 19 (1992): 217-41.

Mazzotti, José Antonio. "Fernando Valverde y los monstruos andinos: criollismo místico en el peregrinaje a Copacabana”. La formación de la cultura virreinal, II: Siglo XVII. Eds. Karl Kohut y Sonia Rose. Madrid: Iberoamericana/Frankfurt am Main: Vervuert, 2004. 439-53.

Mesa, José de, y Teresa Gisbert. "La virgen María en Bolivia: la dialéctica barroca en la representación de María". Barroco andino: memoria del I encuentro internacional. Pamplona: Fundación Visión Cultural/Servicio de Publicaciones de la Universidad de Navarra, 2011. 19-36. 
Mexía, Diego. Primera parte del Parnaso Antártico de obras amatorias. Ed. Trinidad Barrera. Roma: Bulzoni, 1990.

Ocaña, Diego de. Memoria viva de una tierra de olvido: relación del viaje al Nuevo Mundo de 1599 a 1607. Ed. Beatriz Carolina Peña. Barcelona: Paso de Barca, 2013.

Querejazu, Pedro. "El arte barroco en la antigua Audiencia de Charcas, hoy Bolivia”. Barroco Iberoamericano de los Andes a las Pampas. Barcelona: Lunwerg, 1997.

Ramos Gavilán, Alonso. Historia del célebre santuario de Nuestra Señora de Copacabana y sus milagros, e Invención de la Cruz de Tarabuco. Eds. Hans Van den Berg y Andrés Eichmann. Sucre: Archivo y Biblioteca Nacionales de Bolivia, 2015.

Sabena, Julia. "«Con voz heroica y épicos alientos»: sobre el género y las filiaciones del Santuario de Nuestra Señora de Copacabana en Perú (1641) de Fernando de Valverde". Zama 6 (2014): 115-27.

Sabena, Julia. "Unas observaciones en torno al gongorismo peruano: el Santuario de Fernando de Valverde". Revista de crítica literaria latinoamericana 17.83 (1er semestre de 2016): 61-79.

Salles-Reese, Verónica. From Viracocha to the Virgin of Copacabana: representation of the Sacred at Lake Titicaca. Austin: Texas UP, 1997.

Sebastián, Santiago, José de Mesa, y Teresa Gisbert, eds. Arte iberoamericano desde la colonización a la Independencia. Summa Artis: historia general del arte 28. Madrid: Espasa Calpe, 1985.

Sedulio. "Carmen Paschale". Patrologia Latina 19. Paris: J. P. Migne, 1846.

Tubau Moreu, Xavier. Lope de Vega y las polémicas literarias de su época: Pedro de Torres Rámila y Diego de Colmenares. Barcelona: Universidad Autónoma de Barcelona, 2008.

Valverde, Fernando de. Santuario de Nuestra Señora de Copacabana en el Perú: poema Sacro. Lima, 1640.

Van den Berg, Hans. Francisco Tito Yupanqui: siervo de Dios. La Paz: Universidad Católica Boliviana San Pablo, 2012.

Vinatea Recoba, Martina, ed. Epistola de Amarilis a Belardo. Madrid: Iberoamericana/Frankfurt am Main: Vervuert, 2009. 